\title{
Dopaminergic modulation of corticostriatal responses in medium spiny projection neurons from direct and indirect pathways
}

\author{
Edén Flores-Barrera, Bianca J. Vizcarra-Chacón, José Bargas, Dagoberto Tapia and Elvira Galarraga*
}

División de Neurociencias, Instituto de Fisiología Celular, Universidad Nacional Autónoma de México, México City, Federal District, México

\section{Edited by:}

James M. Tepper, Rutgers, The State

University of New Jersey, USA

Reviewed by:

Michael S. Levine, Brain Research

Institute, USA

Jeffery R. Wickens, Okinawa Institute of Science and Technology, Japan

\section{*Correspondence:}

Elvira Galarraga, División de

Neurociencias, Instituto de Fisiología

Celular, Universidad Nacional

Autónoma de México, PO Box: 70-253,

México City, Federal District 04510,

México.

e-mail:egalarra@ifc.unam.mx
Suprathreshold corticostriatal responses recorded from medium spiny neurons (MSNs) from the direct and indirect pathways of the basal ganglia are different. Their differences readily distinguish $D_{1}$ - and $D_{2}$-type receptor expressing MSNs in both bacterial artificial chromosome-transgenic mice and their control littermates as well as in rats: indirect pathway neurons are more excitable than direct pathway neurons revealing autoregenerative spikes underlying their spike trains, whereas direct pathway neurons exhibit more prolonged plateau potentials and spike trains. SFK 81297, a selective agonist for $D_{1}$-class receptors enhanced corticostriatal responses in direct pathway neurons, while quinelorane, a selective agonist for $D_{2}$-class receptors reduced orthodromic and autoregenerative responses in indirect pathway neurons thus making both neuron classes similarly excitable. Because dopaminergic postsynaptic actions target $\mathrm{Ca}_{\vee} 1(\mathrm{~L})$ class voltage-gated calcium channels in MSNs, we hypothesized that these channels are involved and can explain a part of the dopaminergic actions on corticostriatal integration. Both $2.5 \mu \mathrm{M}$ nicardipine and $400 \mathrm{nM}$ calciseptine, selective $\mathrm{Ca}_{\vee} 1$ channel blockers, reduced corticostriatal responses in both $D_{1}$ - and $D_{2}$-receptor expressing neurons, respectively. A previous blockade of $\mathrm{Ca}_{\mathrm{v}} 1$ channels occluded the actions of dopamine agonists in both neuronal classes. In contrast, a $\mathrm{Ca}_{\mathrm{v}} 1$ (L) channel activator, $2.5 \mu \mathrm{M}$ Bay K 8644, enhanced corticostriatal responses in neurons from both pathways. It is concluded that $\mathrm{Ca}_{v} 1$ intrinsic currents mediate a part of the dopaminergic modulation during orthodromic synaptic integration of cortical inputs in both classes of MSNs.

Keywords: $\mathrm{Ca}_{\mathrm{v}} \mathrm{1}$ channels, strionigral pathway, striopallidal pathway, medium spiny neurons, dopamine receptors, corticostriatal pathway

\section{INTRODUCTION}

Striatal dopamine (DA) is involved in initiation of learned procedures (Schultz, 2007). Localization of different DA receptors in medium spiny neurons (MSNs) belonging to direct and indirect pathways of the basal ganglia (Gerfen, 2000) has led to the idea that balanced activity in these two pathways is regulated by opposite actions of DA in each of them: the "two pathways hypothesis" (Albin et al., 1989; Mink, 2003; Redgrave et al., 2010). Both voltage- and current-clamp data in single cells have partially confirmed these assumptions: $\mathrm{D}_{1}$-class receptor $\left(\mathrm{D}_{1} \mathrm{R}\right)$ activation facilitates firing in MSNs of the direct pathway by enhancing $\mathrm{Ca}_{\mathrm{v}} \mathrm{l}(\mathrm{L})$ calcium current, whereas $\mathrm{D}_{2}$-class receptor $\left(\mathrm{D}_{2} \mathrm{R}\right)$ activation represses firing in MSNs of the indirect pathway by decreasing the same current (Surmeier et al., 1995; Hernández-López et al., 1997, 2000). Supposedly, facilitating the direct pathway and preventing activity in the indirect pathway are DA roles when promoting movement (Bateup et al., 2010; Kravitz et al., 2010). These DA receptors use different signaling cascades to target $\mathrm{Ca}_{\mathrm{v}} 1(\mathrm{~L})$ calcium channels (Surmeier et al., 1995; Hernández-López et al., 1997, 2000).

Nonetheless, although clear differences in DA actions can be recorded during direct stimulation experiments (Surmeier et al., 1995, 2007; Galarraga et al., 1997; Hernández-López et al., 1997, 2000; Salgado et al., 2005), these differences have not been observed during more physiological corticostriatal synaptic responses (Flores-Barrera et al., 2010), when neurons are embedded in their rich polysynaptic network where indirect effects can ensue (Albin et al., 1989; Mink, 2003; FloresBarrera et al., 2009; Bateup et al., 2010; Kravitz et al., 2010; Redgrave et al., 2010). Two questions need to be answered: First, if indirect pathway $\mathrm{D}_{2}$-expressing neurons are more excitable than direct pathway neurons (Day et al., 2006; Flores-Barrera et al., 2010) then, it is important to know whether activation of $\mathrm{D}_{1}$-class receptors is strong enough to make direct pathway neurons more excitable, perhaps as excitable as indirect pathway neurons. Secondly, it is also important to know whether $\mathrm{D}_{2}$-class receptor activation is strong enough to decrease significantly the corticostriatal response of indirect pathway neurons. In other words, to test the robustness of dopaminergic actions on corticostriatal responses it is necessary to observe whether DA actions do in fact produce a balance in excitability as the "two pathway hypothesis" postulates. If this is so, it is necessary to know how much margin is available to the system in order to achieve the supposed balance. To answer these questions, we used selective agonists and antagonists of $\mathrm{D}_{1}$ - and $\mathrm{D}_{2}$-class receptors, bacterial artificial chromosome (BAC) transgenic mice to identify the recorded neurons, and 
evoked suprathreshold synaptic responses in which both polysynaptic and intrinsic currents are involved (Flores-Barrera et al., 2009, 2010).

Because both DA receptors and $\mathrm{Ca}_{\mathrm{v}} 1$ channels are found in dendrites of MSNs where most cortical inputs arrive (Freund et al., 1984; Carter and Sabatini, 2004; Kreitzer and Malenka, 2005; Day et al., 2006), and because DA modulation particularly targets $\mathrm{Ca}_{\mathrm{v}} 1$ channels in MSNs (Surmeier et al., 1995; Hernández-López et al., 1997, 2000), the present study focuses in the involvement of this intrinsic current on corticostriatal synaptic integration and its role during dopaminergic modulation. However, the present work was not intended to exclude other possible contributors. It was found that dopaminergic actions expected by the two pathways hypothesis are robust and readily observed upon corticostriatal responses, provided the recorded cells from both pathways are identified and selective pharmacological tools are employed.

\section{MATERIALS AND METHODS}

All experiments were carried out in accordance with the National Institutes of Health Guide for Care and Use of Laboratory Animals and were approved by the Institutional Animal Care Committee of the Universidad Nacional Autónoma de México. BAC-transgenic mice for $\mathrm{D}_{1}$ - and $\mathrm{D}_{2}$-receptors expressing MSNs ( $\mathrm{D}_{1}$ - and $\mathrm{D}_{2}-\mathrm{MSNs}$ ) of 60- to 90-day-old mice were anesthetized, decapitated, and their brains removed and submerged in an iced saline solution containing (in $\mathrm{mM}$ ): $120 \mathrm{NaCl}, 3 \mathrm{KCl}, 25 \mathrm{NaHCO}_{3}, 2 \mathrm{CaCl}_{2}, 1 \mathrm{MgCl}_{2}$, and 11 glucose $\left(33-35^{\circ} \mathrm{C}, 300 \mathrm{mOsm} / \mathrm{l}\right.$ with glucose, $\mathrm{pH} 7.4$, after bubbling with $95 \% \mathrm{O}_{2}$ plus $5 \% \mathrm{CO}_{2}$ ). Briefly, and as previously described in detail, $350 \mu \mathrm{m}$ thick parasagittal slices were cut (Flores-Barrera et al., 2010) on a vibratome and left to equilibrate for at least $1 \mathrm{~h}$ at room temperature in the same saline. Thereafter, slices were transferred to a recording chamber and continuously superfused with the same saline at $33-35^{\circ} \mathrm{C}$. Intracellular recordings were performed from spiny neurons of the dorsal neostriatum using sharp electrodes filled with potassium-acetate $3 \mathrm{M}$ and $1 \%$ biocytin (d.c. resistance $80-120 \mathrm{M} \Omega$ ). Records were obtained with an active bridge electrometer (Neuro Data, Cygnus Technology, Inc., Delaware Water Gap, PA, USA), digitized, and saved for off-line analysis with a personal computer. After recordings, neurons were injected with biocytin for its anatomical identification. Biocytin injected neurons were identified as $\mathrm{D}_{1}$ - or $\mathrm{D}_{2}$-type receptors expressing MSNs. $\mathrm{D}_{1}$ - and $\mathrm{D}_{2}$-type dopaminergic agonists: SKF 81297 and qinelorane, as well as antagonists: SCH 23390 and sulpìride were used. $\mathrm{Ca}_{\mathrm{v}} 1$ (L) type calcium agonist Bay $\mathrm{K} 8644$ and L-type calcium channel blockers, nicardipine (Sigma, St. Louis, MO, USA), and calciseptine (Alomone Labs, Jerusalem, Israel) were dissolved and applied to the bath saline. Most experiments were paired, so that recordings in the presence and absence of bath-applied drugs were compared in the same neuron with nonparametric statistics (Systat v.7., SPSS Inc., Chicago, IL, USA): When $\mathrm{D}_{1}$ and $\mathrm{D}_{2}-\mathrm{MSN}$ s parameters were compared Mann-Whitney's $U$ test was employed. Statistical significance was set at $P<0.05$.

\section{RESULTS}

\section{DOPAMINERGIC MODULATION OF CORTICOSTRIATAL RESPONSES IN MSNS FROM DIRECT AND INDIRECT PATHWAYS}

Medium spiny neurons were identified as belonging to the direct or indirect pathways by double labeling the biocytin-filled and green fluorescent protein positive (GFP+) recorded cells.
Figure 1A shows a suprathreshold corticostriatal response (red) from a $\mathrm{BAC}_{1}$-receptor expressing neuron. Photomicrograph at right shows the double labeled recorded neuron (superimposed eGFP-green and biocytin-red). Figure 1B shows a suprathreshold corticostriatal response (green) from a $\mathrm{BAC} \mathrm{D}_{2}$-receptor expressing neuron. Photomicrograph at right shows the double labeled neuron. Corticostriatal responses in $\mathrm{D}_{1}$-receptor expressing MSN ( $\mathrm{D}_{1}$-MSN) show action potentials of increasing amplitude and a slowly decaying plateau potentials, whereas $\mathrm{D}_{2}$-receptor expressing MSN ( $D_{2}-\mathrm{MSN}$ ) shows a larger but briefer depolarization with firing of inactivating action potentials followed by a quasi exponential decay. Inset in Figure 1A shows superimposition of both recordings to emphasize their differences (Flores-Barrera et al., 2010): area under $\mathrm{D}_{1}$-MSNs response is $10,568 \pm 523 \mathrm{mV} \cdot \mathrm{ms}$ and area under $\mathrm{D}_{2}-\mathrm{MSN}$ response, without including the autoregenerative response, is $8,204 \pm 697 \mathrm{mV} \cdot \mathrm{ms}$, respectively $(n=36 ; P<0.001)$.

Corticostriatal responses evoked with increasing stimulation strength were tested in $\mathrm{D}_{1}$-MSNs with $1 \mu \mathrm{M}$ SKF 81297, a selective $\mathrm{D}_{1}$-class receptor agonist (Figures $2 \mathrm{~A}-\mathrm{C}$, black traces: control; red traces: plus SKF 81297). In all direct pathway neurons recorded, $\mathrm{D}_{1}$-receptor activation enhanced the response, augmenting the depolarization, and the number of action potentials fired. Surprisingly, responses exhibited inactivation of action potentials during synaptic depolarization, a phenomenon more commonly seen in $\mathrm{D}_{2}$-MSNs but rarely seen in $\mathrm{D}_{1}$-MSNs in control conditions (Flores-Barrera et al., 2010). That is, $\mathrm{D}_{1}$-receptor activation could render direct pathway neurons as excitable as

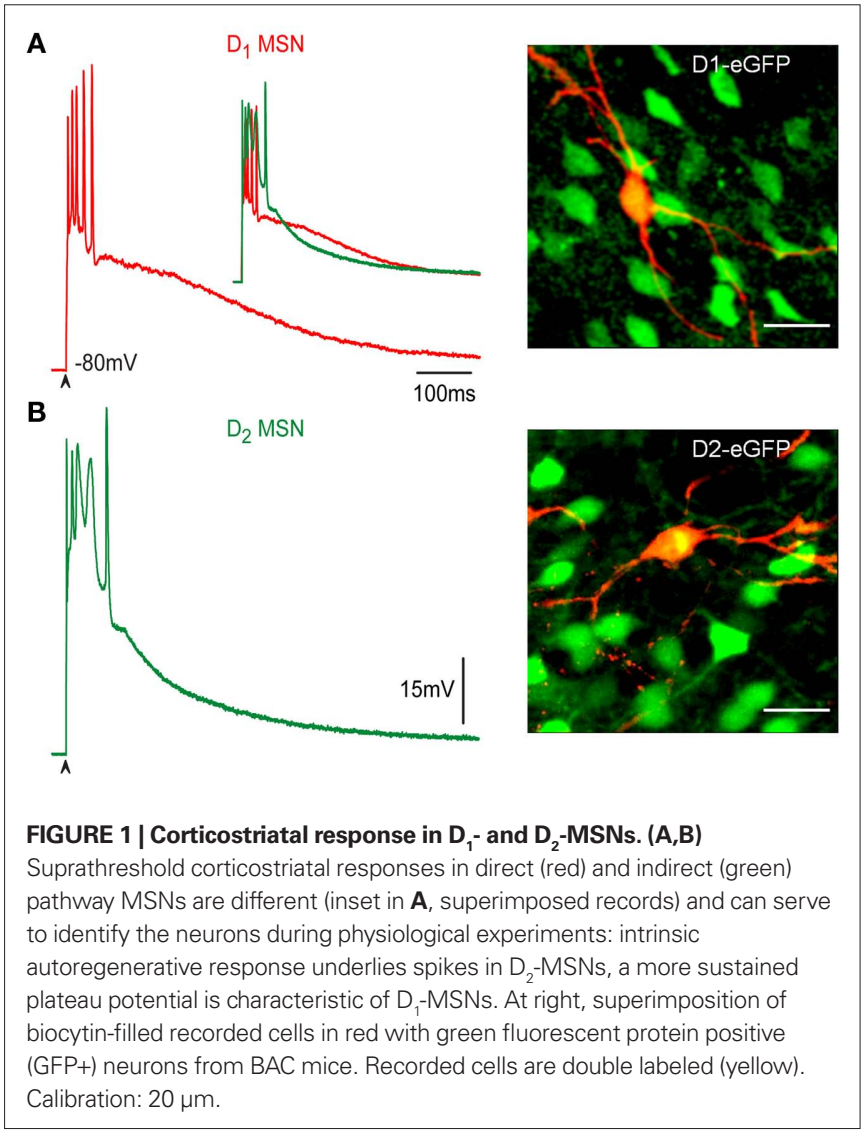




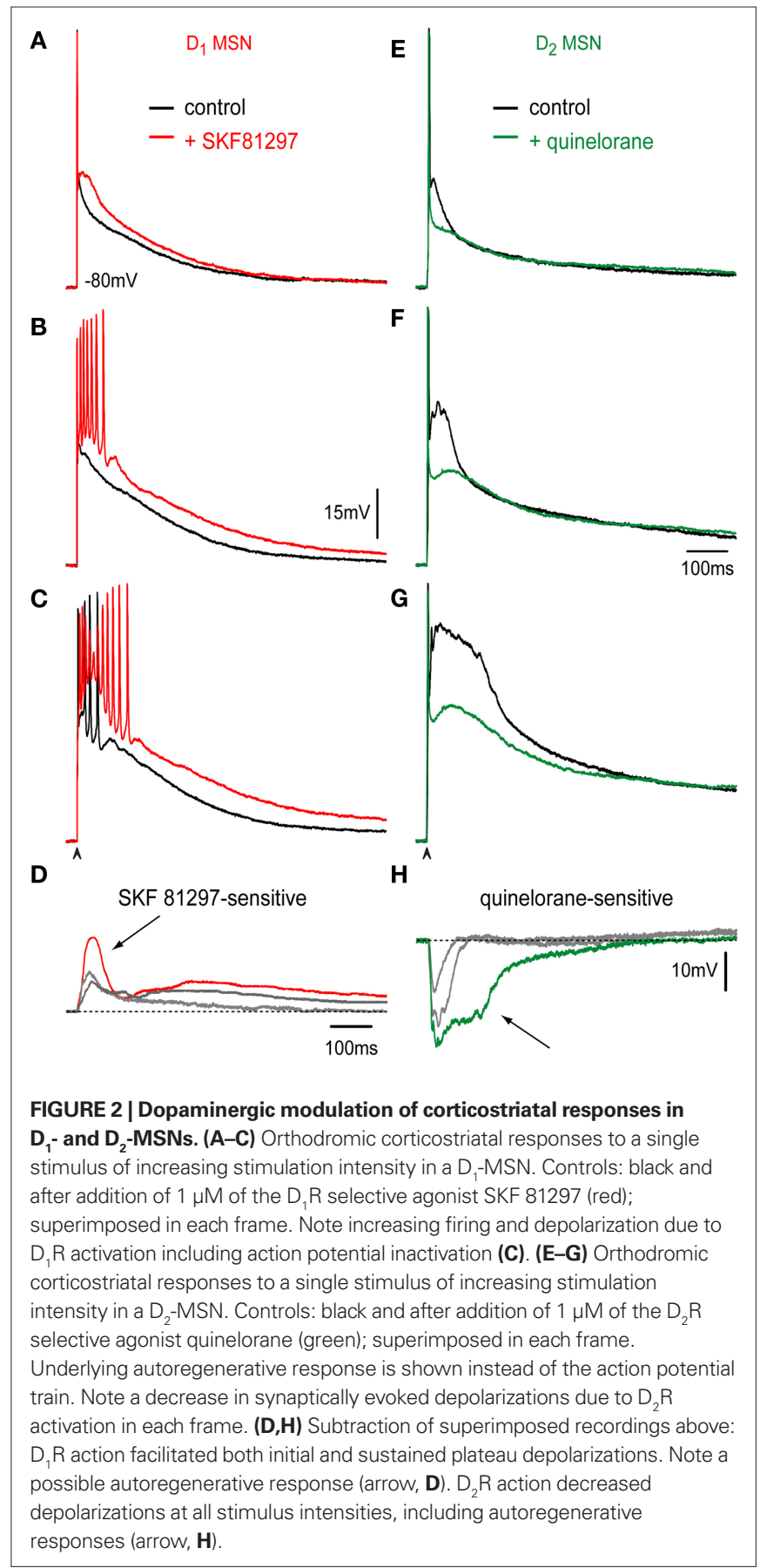

indirect pathway neurons. Action of SKF 81297 was completely blocked by the $\mathrm{D}_{1}$-receptor antagonist $1 \mu \mathrm{M} \mathrm{SCH} 23390(n=3$; not shown). Percentages of depolarization enhancement induced by $\mathrm{D}_{1}$-agonist in the maximal corticostriatal response were $29 \pm 8 \%(n=8 ; P<0.03)$. Figure 2D shows subtractions from the records above. Note that $D_{1}$-receptor activation enhances the corticostriatal response both by prolonging and increasing the plateau potential in a gradual manner and, most importantly, by disclosing an initial underlying autoregenerative response at the initial depolarization during the highest stimulus strength (Figure 2D, arrow).
Corticostriatal responses evoked with increasing stimulation strength were tested in $\mathrm{D}_{2}$-MSNs with $1 \mu \mathrm{M}$ quinelorane, a selective $\mathrm{D}_{2}$-class receptor agonist (Figures $2 \mathrm{E}-\mathrm{G}$, black traces: control; green traces: plus quinelorane). In all indirect pathway neurons $\mathrm{D}_{2}$-receptor activation reduced the response, decreasing the depolarization. In these traces, it was preferred to illustrate the autoregenerative response that commonly underlies the train of action potentials in indirect pathway neurons (Flores-Barrera et al., 2010) to show that $D_{2} R$ action decreases that response. Action of quinelorane was completely blocked by the $\mathrm{D}_{2}$-receptor antagonist $1 \mu \mathrm{M}$ sulpiride $(n=3$; not shown). Percentages of depolarization reduction induced by $\mathrm{D}_{2}$-agonist in the maximal corticostriatal response without including the autoregenerative response were $23 \pm 6 \%(n=10 ; P<0.03)$. That is, $\mathrm{D}_{2}$-receptor activation significantly decreased the synaptic response of indirect pathway neurons. Figure $2 \mathbf{H}$ shows subtractions from the records above. Note that $\mathrm{D}_{2}$-receptor activation decreases the corticostriatal response including the autoregenerative response (Figure $\mathbf{2 H}$, arrow; Bargas et al., 1991; Flores-Barrera et al., 2010).

Taking all the results together it appears that DA actions can balance the excitability of direct and indirect pathway neurons of the basal ganglia by both enhancing the excitability of direct and repressing the excitability of indirect pathway neurons (Galarraga et al., 1997; Carter and Sabatini, 2004; Liu et al., 2004; Day et al., 2008) as the "two pathways hypothesis" requires. Areas under synaptic responses for each cell type after DA receptors activation and with respect to their own controls are 9,124 $\pm 609 \mathrm{mV} \cdot \mathrm{ms}$ vs. $11,810 \pm 1,264 \mathrm{mV} \cdot \mathrm{ms}$ for $\mathrm{D}_{1}$-MSNs $(n=8, P<0.03)$ and $8,950 \pm 1,006 \mathrm{mV} \cdot \mathrm{ms}$ vs. $7,173 \pm 687 \mathrm{mV} \cdot \mathrm{ms}$ for $\mathrm{D}_{2}$-MSNs $(n=10$; $P<0.03)$.

\section{Ca $_{v} 1$ CALCIUM CURRENT CONTRIBUTION DURING CORTICOSTRIATAL RESPONSES}

Both DA receptors and $\mathrm{Ca}_{\mathrm{v}} 1(\mathrm{~L})$ calcium channels are found in dendrites of MSNs where cortical inputs arrive to generate corticostriatal responses (Freund et al., 1984; Carter and Sabatini, 2004; Kreitzer and Malenka, 2005; Day et al., 2006). $\mathrm{Ca}_{\mathrm{v}} 1$ channels are activated during corticostriatal responses in non-identified MSNs (Galarraga et al., 1997; Adermark and Lovinger, 2007; FloresBarrera et al., 2009). These channels are also a main target for $\mathrm{D}_{1}$ - and $\mathrm{D}_{2}$-receptors signaling during direct somatic stimulation (Hernández-López et al., 1997, 2000). Finally, $\mathrm{Ca}_{\mathrm{v}} 1$ channels have also been shown to participate in the generation of down- to upstate voltage transitions in MSNs (Vergara et al., 2003). Therefore, it is logical to infer that they may be involved in the evoked corticostriatal responses in both direct and indirect MSNs, however, this last point has not been proved.

Figures 3A,B show that the $\mathrm{Ca}_{\mathrm{v}} 1$ channel blocker, $400 \mathrm{nM}$ calciseptine, reduces corticostriatal responses in both $\mathrm{D}_{1}$ - and $\mathrm{D}_{2}$-MSNs. Superimposed records in control (black) and in the presence of calciseptine (blue) confirm that intrinsic calcium currents are activated by corticostriatal transmission in both classes of projection neurons. Blockade of $\mathrm{Ca}_{\mathrm{v}} 1$ channels in $\mathrm{D}_{1}-\mathrm{MSNs}$ decreased the corticostriatal response by $29 \pm 2 \%(n=7 ; P<0.05)$, while it decreased the response by $29 \pm 2 \%(n=8 ; P<0.007)$ in $\mathrm{D}_{2}$-MSNs. Similar reductions were observed after $2.5 \mu \mathrm{M}$ nicardipine (see Figure 4). Note two rising components in $\mathrm{D}_{1}$-MSNs: 


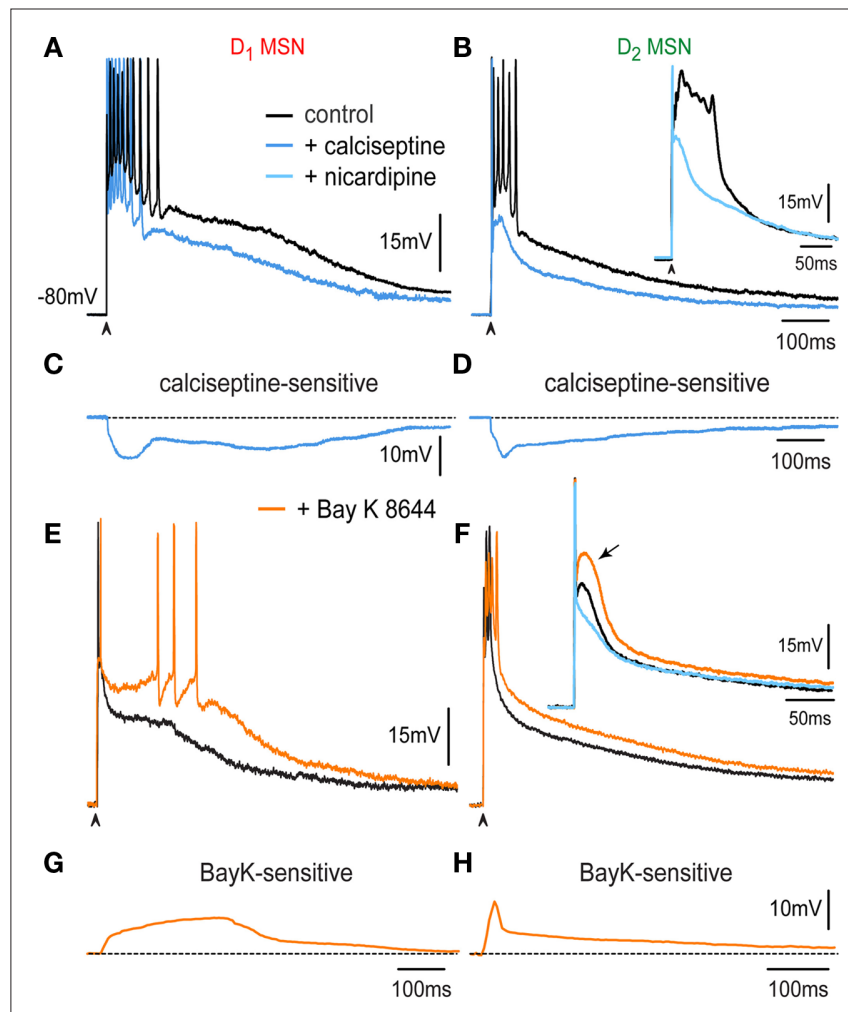

FIGURE 3 | Contribution of $\mathrm{Ca}_{\mathrm{v}} 1$ calcium current during the corticostriatal response in $\mathbf{D}_{1}$ - and $\mathbf{D}_{2}-\mathbf{M S N s}$. (A) Superimposed records: in control (black) and in the presence of $400 \mathrm{nM}$ calciseptine (blue) in a $\mathrm{D}_{1}-\mathrm{MSN}$. (B) Superimposed records: in control (black) and in the presence of $400 \mathrm{nM}$ calciseptine (blue) in a $D_{2}-M S N$. Note briefer train of action potentials in $\mathrm{D}_{2}-\mathrm{MSN}$ s as compared to $\mathrm{D}_{1}-\mathrm{MSNs}$ (cf. $\mathbf{A}, \mathbf{B}$ ). Inset: shows the autoregenerative response that underlies the train of action potentials in $\mathrm{D}_{2}$-MSNs (cf. Figure 2), before (black trace) and during $2.5 \mu \mathrm{M}$ nicardipine (light blue). (C,D) Subtractions of superimposed records above disclose the calciseptine-sensitive component in $\mathrm{D}_{1}$ - and $\mathrm{D}_{2}-\mathrm{MSN}$ s. Note initial and late rising components in $\mathrm{D}_{-}-\mathrm{MSN}$, and only the initial followed by continuous decay in $\mathrm{D}_{2}-\mathrm{MSN}$ s. (E) Superimposed records: in control (black) and in the presence of $2.5 \mu \mathrm{M}$ Bay K 8644 (orange) in a $\mathrm{D}_{1}-\mathrm{MSN}$. (F) Superimposed records: in control (black) and in the presence of $2.5 \mu \mathrm{M}$ Bay K 8644 (orange) in $\mathrm{D}_{2}-\mathrm{MSN} \mathrm{Ca}_{\mathrm{v}} 1$ agonist prolonged the plateau potential and induced the firing of more action potentials in $\mathrm{D}_{1}-\mathrm{MSN}$, whereas it depolarized the response of $D_{2}-M S N s$ along its decay. Inset in (F) shows that Bay $K 8644$ helps in eliciting an autoregenerative response in $\mathrm{D}_{2}-\mathrm{MSNs}$. (G,H) Subtraction of Bay K 8644 actions: Note an increasing and sustained depolarization in $\mathrm{D}_{1}-\mathrm{MSNs}$, and a decaying depolarization after the initial peak in $\mathrm{D}_{2}-\mathrm{MSNs}$.

initial and late, and only an initial component plus a prolonged decay in $\mathrm{D}_{2}$-MSNs. Subtractions of superimposed records disclose the calciseptine-sensitive component (Figures 3C,D; FloresBarrera et al., 2010). Areas under responses for each cell type after blockers of $\mathrm{Ca}_{\mathrm{v}} 1$ channels with respect to their own controls are

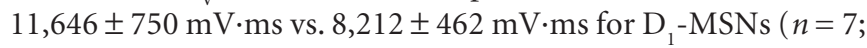
$P<0.03)$ and $7,876 \pm 864 \mathrm{mV} \cdot \mathrm{ms}$ vs. $5,611 \pm 675 \mathrm{mV} \cdot \mathrm{ms}$ for $\mathrm{D}_{2}$-MSNs $(n=8 ; P<0.007)$. Inset in Figure 3B shows in other indirect pathway neuron, a reduction in the orthodromic autoregenerative response after $2.5 \mu \mathrm{M}$ nicardipine.

We next tested the effects of the $\mathrm{Ca}_{\mathrm{v}} 1(\mathrm{~L})$ calcium agonist Bay $\mathrm{K} 8644$ $(2.5-5 \mu \mathrm{M})$ on the corticostriatal response. Superimposed records: in control (black) and in the presence of $2.5 \mu \mathrm{M}$ Bay K 8644 (orange) in

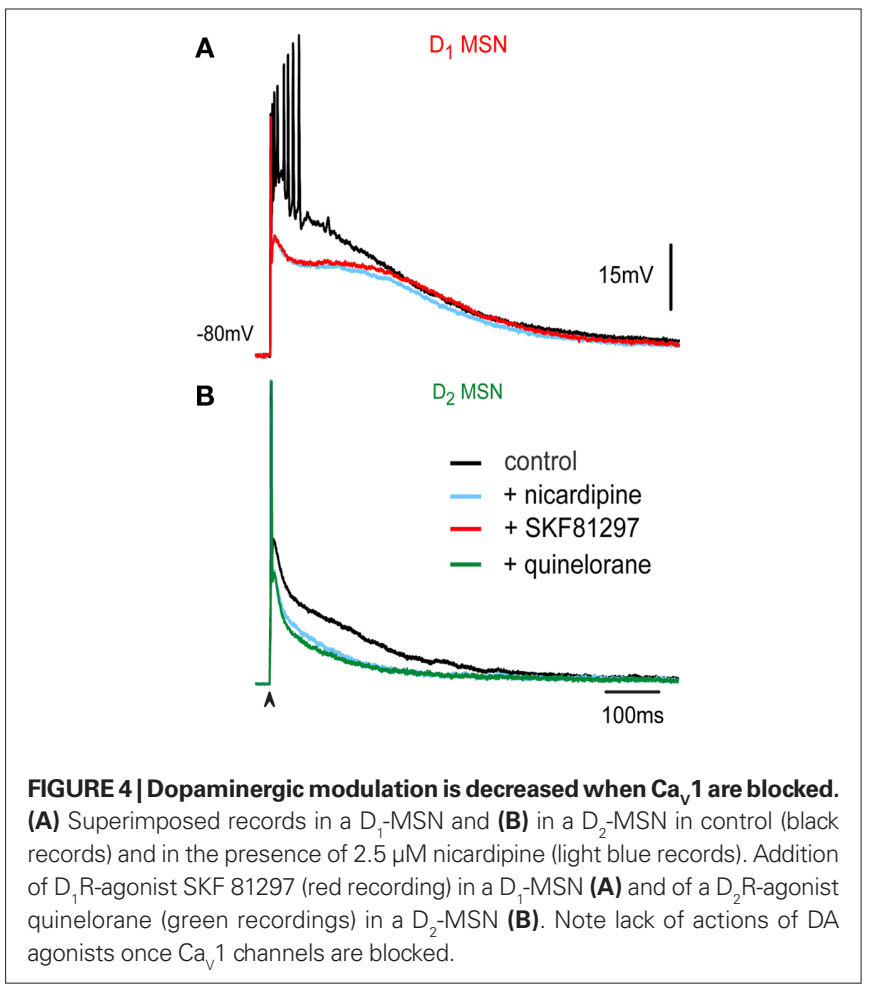

a $\mathrm{D}_{1}-\mathrm{MSN}$ (Figure 3E) and in a $\mathrm{D}_{2}-\mathrm{MSN}$ (Figure 3F) show that the $\mathrm{Ca}_{\mathrm{v}} 1$ agonist prolongs the plateau potential and induces the firing of more action potentials in $\mathrm{D}_{1}$-MSNs, whereas it depolarized the response of $\mathrm{D}_{2}$-MSNs along its entire decay. Bay K 8644 helps in eliciting an autoregenerative response in $\mathrm{D}_{2}$-MSNs (inset in Figure 3F). Bay K 8644 actions show increasing and sustained depolarizations in $\mathrm{D}_{1}$-MSNs (Figure 3G), and a decaying depolarization after the initial peak in $\mathrm{D}_{2}$-MSNs (Figure 3H). Inset in Figure 3F shows in another indirect pathway neuron, after $2.5 \mu \mathrm{M}$ nicardipine in the presence of Bay K 8644 a reduction in orthodromic autoregenerative response.

Because the actions of calcium blockers was so similar in both neuronal classes, the different roles that $\mathrm{Ca}_{\mathrm{v}} 1$ channels accomplish in each response, as disclosed by Bay K 8644, suggests that other synaptic or intrinsic currents are in charge of $\mathrm{Ca}_{\mathrm{v}} 1$ channels regulation, perhaps at dendritic sites.

Areas under synaptic responses for each cell type after $\mathrm{Ca}_{\mathrm{v}} 1$ agonist Bay $\mathrm{K} 8644$ with respect to their own controls are $11,821 \pm 1,324 \mathrm{mV} \cdot \mathrm{ms}$ vs. $15,306 \pm 1,600 \mathrm{mV} \cdot \mathrm{ms}$ for $\mathrm{D}_{1}$-MSNs $(n=4 ; P<0.05)$ and $7,919 \pm 2,178 \mathrm{mV} \cdot \mathrm{ms} v s .11,308 \pm 2,600 \mathrm{mV} \cdot \mathrm{ms}$ for $\mathrm{D}_{2}$-MSNs $(n=4 ; P<0.05)$.

\section{DOPAMINERGIC MODULATION IS OCCLUDED WHEN Ca 1 1 CHANNELS ARE BLOCKED}

Figure $4 \mathrm{~A}$ shows superimposed corticostriatal responses in a representative $\mathrm{D}_{1}-\mathrm{MSN}$ in control (black), in the presence of $2.5 \mu \mathrm{M}$ nicardipine (light blue) and after application of the $\mathrm{D}_{1}$-class receptor agonist $1 \mu \mathrm{M}$ SKF 81297 (red). Note absence of action of $\mathrm{D}_{1}$-agonist after blockade of $\mathrm{Ca}_{\mathrm{v}} 1$ channels. Figure $4 \mathrm{~B}$ shows superimposed corticostriatal responses in a representative $\mathrm{D}_{2}$-MSN in control (black), in the presence of $2.5 \mu \mathrm{M}$ nicardipine (light blue) and after application of the $\mathrm{D}_{2}$-class receptor agonist $1 \mu \mathrm{M}$ quinelorane 
(green). Note absence of action of $\mathrm{D}_{2}$-agonist after blockade of $\mathrm{Ca}_{\mathrm{v}} 1$ channels. These experiments suggest that $\mathrm{Ca}_{\mathrm{v}} 1$ channels are a major target of DA modulation during corticostriatal integration.

\section{DISCUSSION}

Corticostriatal responses of $\mathrm{D}_{1}$ - and $\mathrm{D}_{2}$-MSNs constitute an "electrophysiological footprint" that readily distinguishes between direct and indirect pathway neurons (Flores-Barrera et al., 2010) because dendritic excitability, and therefore, corticostriatal integration is different in $\mathrm{D}_{1}$ - and $\mathrm{D}_{2}$-MSNs when all synaptic and intrinsic currents are in place (Day et al., 2008; Flores-Barrera et al., 2010). The present work demonstrated: (1) A selective dopaminergic $\mathrm{D}_{1}$-class receptor mediated increase in firing and depolarization of the corticostriatal response in $\mathrm{D}_{1}$-MSNs in such a way as to approach the level of excitability found in $\mathrm{D}_{2}$-MSNs. (2) A selective dopaminergic $\mathrm{D}_{2}$-class receptor mediated a significant decrease in firing and depolarization of the corticostriatal response in $\mathrm{D}_{2}$-MSNs. (3) $\mathrm{Ca}_{\mathrm{v}} 1$ (L) calcium currents contribute to corticostriatal integration in both $\mathrm{D}_{1}$ - and $\mathrm{D}_{2}$-MSNs; including the autoregenerative response underlying the train of spikes characteristic of $\mathrm{D}_{2}$-MSNs. (4) Blockade of $\mathrm{Ca}_{\mathrm{v}} 1$ channels occluded the actions of selective DA receptor agonists in their respective responsive neurons from the direct and indirect pathways. (5) By acting in both pathways simultaneously DA may balance the excitability of the neurons from both basal ganglia pathways to make $\mathrm{D}_{2}$-MSNs less excitable than $\mathrm{D}_{1}-\mathrm{MSN}$, if necessary, thus reversing their responsiveness to cortical commands. These findings show that there is enough margin to tune up the excitability of the neurons from both pathways, upon demand. This tuning capability is very probably lost during Parkinsonism (Flores-Barrera et al., 2010).

The present work did not exclude, however, the possible participation of other calcium channels (Carter and Sabatini, 2004; Salgado et al., 2005; Higley and Sabatini, 2010) in corticostriatal integration and only underlines the importance of $\mathrm{Ca}_{\mathrm{v}} 1$ channels.

$\mathrm{Ca}_{\mathrm{v}} 1$ channels are positioned near cortical glutamatergic synapses in MSNs dendrites (Freund et al., 1984; Carter and Sabatini, 2004; Higley and Sabatini, 2010), a strategic location to participate in corticostriatal integration. However, in spite of voltage- and current-clamp recordings during direct stimulation experiments in single cells agree with the assumptions of the "two pathways hypothesis," that are, first, $\mathrm{D}_{1}$-class receptor activation facilitates firing in $\mathrm{D}_{1}$-MSNs during direct somatic stimulation of single cells (Hernández-López et al., 1997) and enhances $\mathrm{Ca}_{\mathrm{v}} 1$ calcium current in isolated neurons (Surmeier et al., 1995), and secondly, $\mathrm{D}_{2}$-class receptor activation represses firing in MSNs of the indirect pathway by decreasing the same current (Hernández-López et al., 1997, 2000; Day et al., 2008), the fact is that in trying to find these differences during striatal network activity, in vivo, the expectations of the two pathways hypothesis become very variable and even contradictory (Liang et al., 2008; Kravitz et al., 2010).

It is argued that an undisputed electrophysiological evidence of the two pathways hypothesis is lacking during more physiological conditions because indirect circuit influences distort or increase the variability of the responses (e.g., Kravitz et al., 2010). Therefore, in this work we wanted to observe whether dopaminergic actions expected by the "two pathways hypothesis" is robust enough to be preserved during corticostriatal suprathreshold dendritic integration which is known to activate polysynaptic pathways as well as several intrinsic inward and outward currents (Flores-Barrera et al., 2009, 2010). This implies to test DA actions during more physiological responses.

The present experimental work demonstrates the main postulate of the "two pathways hypothesis," that is, that the excitability of neurons from both basal ganglia pathways can reach a dynamic balance due to both $\mathrm{D}_{1}$ - and $\mathrm{D}_{2}$-class receptors activation which enhance and decrease, respectively, the corticostriatal responses of direct and indirect pathway neurons. DA actions have a wide range of operation since $\mathrm{D}_{1}-\mathrm{MSN}$ can become more excitable than $\mathrm{D}_{2}-\mathrm{MSN}$ if necessary. Therefore, the present data support DA role as that of balancing both basal ganglia pathways. Targeting of $\mathrm{Ca}_{\mathrm{v}} 1$ channels was somehow expected since the gating of voltage-dependent and ligand-gated (ionotropic) ion channels in the dendritic membrane, as well as long-term synaptic plasticity, depend on calcium entry through these channels (Snyder, et al., 2000; Hallett et al., 2006; Adermark and Lovinger, 2007).

Variable results and randomness in firing found in vivo more physiological situations (Kostal et al., 2007) are attributed to a population or vectorial neural coding (Wu et al., 2002), evidence of which, has been obtained for the striatal microcircuit (Carrillo-Reid et al., 2008, 2009). Thus, although the present work supports potent and robust DA postsynaptic actions in a more physiological situation, several groups have also reported potent presynaptic actions on terminals making contact with each class of projection neuron (FloresHernández et al., 1997; Guzmán et al., 2003; Bamford et al., 2004; Tecuapetla et al., 2007) and following determined connections rules (Taverna et al., 2008), suggesting the possibility of a concomitant dynamic regulation of synaptic weights as well as dopaminergic regulation of striatal interneurons (Tepper et al., 2004).

\section{CONCLUSION}

Dopamine plays a fundamental role in normal basal ganglia function, the deficits arising from reductions in the sustained stimulation of DA receptors show a rather wide involvement in behavioral processes (Schultz, 2007). After DA depletion, a reduction in the corticostriatal response was reported in substance $\mathrm{P}$ expressing MSNs whereas an enhancement in the response was observed in enkephalin expressing MSNs, partially explained by a decrease of synaptic GABAergic connections among MSNs (Flores-Barrera et al., 2010). In contrast, the present study shows that the dopaminergic $\mathrm{D}_{1} \mathrm{R}$ activation increased the corticostriatal response in $\mathrm{D}_{1}$-MSN up to the point of action potential inactivation as that observed in $\mathrm{D}_{2}$-MSNs whereas $\mathrm{D}_{2} \mathrm{R}$ activation depressed the corticostriatal response in $\mathrm{D}_{2}$-MSNs and decreases duration and amplitude of calcium autoregenerative responses recorded in these neurons. Therefore, dopaminergic DA receptors actions tend to equalize the excitability of MSNs from both pathways.

Because modulation of $\mathrm{Ca}_{\mathrm{v}} 1$ channels is lost in the absence of DA, the changes observed in the corticostriatal response after DA depletion: a decrease in the depolarizing plateau of SP+ expressing MSNs, and a greater intrinsic excitability of ENK+ expressing MSNs can be readily explained. The end result is that both classes of MSNs lose their ability to balance their activity during Parkinsonism (Flores-Barrera et al., 2010), being, perhaps, a main cause of movement impairment.

It is concluded that strong cortical stimulation can overcome all these indirect network effects so that the present results support the DA role expected by the "two pathways hypothesis." 


\section{ACKNOWLEDGMENTS}

We thank Antonio Laville and Gabriela X Ayala for technical support and advice. This work was supported by grants from a Project Program grant IMPULSA 03 from UNAM, by Consejo Nacional

\section{REFERENCES}

Adermark, L., and Lovinger, D. M. (2007). Combined activation of L-type Ca2+ channels and synaptic transmission is sufficient to induce striatal long-term depression. J. Neurosci.27, 6781-6787.

Albin, R. L., Young, A. B., and Penney, J. B. (1989). The functional anatomy of basal ganglia disorders. Trends Neurosci. 12, 366-375.

Bamford, N. S., Zhang, H., Schmitz, Y., Wu, N. P., Cepeda, C., Levine, M. S., Schmauss, C., Zakharenko, S. S., Zablow, L., and Sulzer, D. (2004). Heterosynaptic dopamine neurotransmission selects sets of corticostriatal terminals. Neuron 42, 653-663.

Bargas, J., Galarraga, E., and Aceves, J. (1991). Dendritic activity on neostriatal neurons as inferred from somatic intracellular recordings. Brain Res. 539, 159-163.

Bateup, H. S., Santini, E., Shen, W., Birnbaum, S., Valjent, E., Surmeier, D. J., Fisone, G., Nestler, E. J., and Greengard, P. (2010). Distinct subclasses of medium spiny neurons differentially regulate striatal motor behaviors. Proc. Natl. Acad. Sci. U.S.A. 107, 14845-14850.

Carrillo-Reid, L., Tecuapetla, F., Tapia, D., Hernandez-Cruz, A., Galarraga, E., Drucker-Colin, R., and Bargas, J. (2008). Encoding network states by striatal cell assemblies. J. Neurophysiol. 99, 1435-1450.

Carrillo-Reid, L., Tecuapetla, F., Vautrelle, N., Hernandez, A., Vergara, R., Galarraga, E., and Bargas, J. (2009). Muscarinic enhancement of persistent sodium current synchronizes striatal medium spiny neurons. $J$. Neurophysiol. 102, 682-690.

Carter, A. G., and Sabatini, B. L. (2004). State-dependent calcium signaling in dendritic spines of striatal medium spiny neurons. Neuron 44, 483-493.

Day, M., Wang, Z., Ding, J., An, X., Ingham, C. A., Shering, A. F., Wokosin, D., Ilijic, E., Sun, Z., Sampson, A. R., Mugnaini, E., Deutch, A. Y., Sesack, S. R., Arbuthnott, G. W., and Surmeier, D. J. (2006). Selective elimination of glutamatergic synapses on striatopallidal neurons in Parkinson disease models. Nat. Neurosci. 9, 251-259.

Day, M., Wokosin, D., Plotkin, J. L., Tian, X., and Surmeier, D. J. (2008). Differential excitability and modulation of striatal medium spiny neuron dendrites. J. Neurosci. 28, 11603-11614.
Flores-Barrera, E., Laville, A., Plata, V., Tapia, D., Bargas, J., and Galarraga, E. (2009). Inhibitory contribution to suprathreshold corticostriatal responses: an experimental and modeling study. Cell. Mol. Neurobiol. 29, 719-731.

Flores-Barrera, E., Vizcarra-Chacón, B. J., Tapia, D., Bargas, J., and Galarraga, E. (2010). Different corticostriatal integration in spiny projection neurons from direct and indirect pathways. Front. Syst. Neurosci. 4:15. doi: 10.3389/fnsys.2010.00015

Flores-Hernández, J., Galarraga, E., and Bargas, J. (1997). Dopamine selects glutamatergic excitatory inputs to the neostriatum. Synapse 25, 185-195.

Freund, T. F., Powell, J. F., and Smith, A. D. (1984). Tyrosine hydroxylaseimmunoreactive boutons in synaptic contact with identified striatonigral neurons, with particular reference to dendritic spines. Neuroscience 13, 1189-1215.

Galarraga, E., Hernández-López, S., Reyes, A., Barral, J., and Bargas, J. (1997). Dopamine facilitates EPSPs through an L-type Ca2+-conductance. Neuroreport 8, 2183-2186.

Gerfen, C. R. (2000). Molecular effects of dopamine on striatal-projection pathways. Trends Neurosci. 23, S64-S70.

Guzmán, J. N., Hernandez, A., Galarraga, E., Tapia, D., Laville, A., Vergara, R., Aceves, J., and Bargas, J. (2003). Dopaminergic modulation of axon collaterals interconnecting spiny neurons of the rat striatum. J. Neurosci. 23, 8931-8940.

Hallett, P. J., Spoelgen, R., Hyman, B. T., Standaert, D. G., and Dunah, A. W. (2006). Dopamine D1 activation potentiates striatal NMDA receptors by tyrosine phosphorylation-dependent subunit trafficking. J. Neurosci. 26, 4690-4700.

Hernández-López, S., Bargas, J., Surmeier, D. J., Reyes, A., and Galarraga, E. (1997). D1 receptor activation enhances evoked discharge in neostriatal medium spiny neurons by modulating an L-type Ca2+-conductance. J. Neurosci. 17, 3334-3342.

Hernández-López, S., Tkatch, T., PérezGarci, E., Galarraga, E., Bargas, J., Hamm, H., and Surmeier, D. J. (2000). D2 dopamine receptors in striatal medium spiny neurons reduce L-type $\mathrm{Ca} 2+$ currents and excitability through a novel PLCB1/IP3/calcineurin signaling cascade. J. Neurosci. 20, 8987-8995.

de Ciencia y Tecnología (Mexico) Grant 98004, and by grants from Direccion General de Asuntos del Personal Académico. Universidad Nacional Autónoma de México: IN205610 and IN206010 to José Bargas and Elvira Galarraga.

Higley, M. J., and Sabatini, B. L. (2010) Competitive regulation of synaptic $\mathrm{Ca}^{2+}$ influx by $\mathrm{D} 2$ dopamine and $\mathrm{A} 2 \mathrm{~A}$ adenosine receptors. Nat. Neurosci. 13, 958-967.

Kostal, L., Lansky, P., and Rospars, J. P. (2007). Neuronal coding and spiking randomness. Eur. J. Neurosci. 26, 2693-2701.

Kravitz, A. V., Freeze, B. S., Parker, P. R., Kay, K., Thwin, M. T., Deisseroth, K., and Kreitzer, A. C. (2010). Regulation of parkinsonian motor behaviours by optogenetic control of basal ganglia circuitry. Nature 466, 622-626.

Kreitzer,A.C., and Malenka, R. C. (2005). Dopamine modulation of state dependent endocannabinoid release and long-term depression in the striatum. J. Neurosci. 25, 10537-10545.

Liang, L., DeLong, M. R., and Papa, S. M. (2008). Inversion of dopamine responses in striatal medium spiny neurons and involuntary movements. J. Neurosci. 28, 7537-7547.

Liu, J. C., DeFazio, R. A., Espinosa-Jeffrey, A., Cepeda, C., de Vellis, J., and Levine, M. S. (2004). Calcium modulates dopamine potentiation of $\mathrm{N}$-methylD-aspartate responses: electrophysiological and imaging evidence. $J$. Neurosci. Res. 76, 315-322.

Mink, J. W. (2003). The basal ganglia and involuntary movements: impaired inhibition of competing motor patterns. Arch. Neurol. 60, 1365-1368.

Redgrave, P., Rodriguez, M., Smith, Y., Rodriguez-Oroz, M. C., Lehericy, S., Bergman, H., Agid, Y, Delong, M. R., and Obeso, J.A. (2010). Goal-directed and habitual control in the basal ganglia: implications for Parkinson's disease. Nat. Rev. Neurosci. 11, 760-772.

Salgado, H., Tecuapetla, F., Perez-Rosello, T., Perez-Burgos, A., Perez-Garci, E., Galarraga, E., and Bargas, J. (2005). A reconfiguration of $\mathrm{CaV} 2 \mathrm{Ca}^{2+}$ channels current and its dopaminergic D2 modulation in developing neostriatal neurons. J. Neurophysiol. 94, 3771-3787.

Schultz, W. (2007). Multiple dopamine functions at different time courses. Annu. Rev. Neurosci. 30, 259-288.

Snyder, G. L., Allen, P. B., Fienberg, A. A., Valle, C. G., Huganir, R. L., Nairn, A.C., and Greengard, P. (2000). Regulation of phosphorylation of the GluR1 AMPA receptor in the neostriatum by dopamine and psychostimulants in vivo. J. Neurosci. 20, 4480-4488.

Surmeier, D. J., Bargas, J., Hemmings, H. C. Jr., Nairn, A. C., and Greengard P.
(1995). Modulation of calcium currents by a D1 dopaminergic protein kinase/phosphatase cascade in rat neostriatal neurons. Neuron 14, 385-397.

Surmeier, D. J., Ding, J., Day, M., Wang, Z., and Shen, W. (2007). D1 and D2 dopamine-receptor modulation of striatal glutamatergic signaling in striatal medium spiny neurons. Trends Neurosci. 30, 228-235.

Taverna, S., Ilijic, E., and Surmeier, D. J. (2008). Recurrent collateral connections of striatal medium spiny neurons are disrupted in models of Parkinson's disease. J. Neurosci. 28, 5504-5512.

Tecuapetla, F., Carrillo-Reid, L., Bargas, J., and Galarraga, E. (2007). Dopaminergic modulation of short term synaptic plasticity at striatal inhibitory synapses. Proc. Natl. Acad. Sci. U.S.A. 104, 10258-10263.

Tepper, J. M., Koós, T., and Wilson, C. J. (2004). GABAergic microcircuits in the neostriatum. Trends Neurosci. 27, 662-669.

Vergara, R., Rick, C., Hernández-López, S., Laville, J.A., Guzmán, J. N., Galarraga, E., Surmeier, D. J., and Bargas, J. (2003). Membrane potential oscillations of striatal medium spiny neurons in a corticostriatal slice. J. Physiol. 553, 169-182.

Wu, S., Amari, S., and Nakahara, H. (2002). Population coding and decoding in a neural field: a computational study. Neural Comput. 14, 999-1026.

Conflict of Interest Statement: The authors declare that the research was conducted in the absence of any commercial or finantcial relationships that could be construed as a potential conflict of interest.

Received: 17 December 2010; paper pending published:06 March 2011; accepted: 15 March 2011; published online: 29 March 2011.

Citation: Flores-Barrera E, VizcarraChacón BJ, Bargas J, Tapia D and Galarraga E(2011) Dopaminergicmodulation of corticostriatal responses in medium spiny projection neurons from direct and indirect pathways. Front. Syst. Neurosci. 5:15. doi: 10.3389/fnsys.2011.00015 Copyright (c) 2011 Flores-Barrera, VizcarraChacón, Bargas, Tapia and Galarraga. This is an open-access article subject to an exclusive license agreement between the authors and Frontiers Media SA, which permits unrestricted use, distribution, and reproduction in any medium, provided the original authors and source are credited. 